\title{
Intenção de compra de produtos locais em consumidores de estados brasileiros de alto sentimento bairrista
}

Esta pesquisa objetivou identificar se há relação entre o sentimento bairrista e a intenção de compra de produtos locais. Foram selecionados os estados brasileiros: Pernambuco e Rio Grande do Sul, pois, constam na literatura científica como fortes características bairristas. Adaptou-se os itens da CETSCALE para uma configuração de consumo local, gerando dois formulários, um para cada estado, e disponibilizados online entre junho e julho de 2019 , obtendo amostra de 229 respondentes. Constatou-se alta porcentagem do sentimento bairrista em ambos estados, com superioridade para o sentimento entre os pernambucanos. Porém quando estabelecida a relação com o consumo, não se identificou influência para a não-compra de produtos de outras regiões, apesar de percebida a intenção de valorização do consumo de produtos locais.

Palavras-chave: Bairrismo; Comportamento do consumidor; CETSCALE; Pernambuco; Rio Grande do Sul.

\section{Intent to purchase local products from consumers of Brazilian high- feeling states 'bairrista'}

This research aimed to identify if there is a relationship between the local feeling and the intention to buy local products. The Brazilian states were selected: Pernambuco and Rio Grande do Sul, as they appear in the scientific literature as strong 'bairristas' characteristics. The CETSCALE items were adapted to a local consumption configuration, generating two forms and made available online between June and July 2019, obtaining a sample of 229 respondents. A high percentage of the feeling of 'bairrista' was verified in both states, with superiority among the Pernambuco. However, when the relationship with consumption was established, there was no influence on the non-purchase of products from other regions, despite the perceived intention of valuing the consumption of local products.

Keywords: Bairrismo; Consumer behavior; CETSCALE; Pernambuco; Rio Grande do Sul.

Topic: Marketing e Estratégias Mercadológicas

Reviewed anonymously in the process of blind peer
Received: 07/04/2021

Approved: 04/06/2021
João Henriques de Sousa Júnior (10)

Universidade Federal de Santa Catarina, Brasil

http://lattes.cnpq.br/1315554826473761

http://orcid.org/0000-0001-8589-8101

sousajunioreu@hotmail.com

\section{Weverson Soares Santos}

Universidade Federal de Santa Catarina, Brasi

http://lattes.cnpq.br/7544083106111472

http://orcid.org/0000-0003-1358-401X

weverson ss@hotmail.com

Rudimar Antunes da Rocha (i)

Universidade Federal de Santa Catarina, Brasil

http://lattes.cnpq.br/3021645851881947

http://orcid.org/0000-0003-2554-2896

rrudimar@hotmail.com
Referencing this:

SOUSA JÚNIOR, J. H.; SANTOS, W. S.; ROCHA, R. A.. Intenção de compra de produtos locais em consumidores de estados brasileiros de alto sentimento bairrista. Revista Brasileira de Administração Científica, v.12, n.2, p.23-38, 2021. DOI: 


\section{INTRODUÇÃO}

O estudo do comportamento do consumidor tem sido pauta de interesse desde as décadas de 1960 e 1970, onde, em seus estágios iniciais de desenvolvimento, era denominado de comportamento do comprador (SOLOMON, 2016). No decorrer das décadas, muitos aspectos começaram a se demonstrar influenciadores no processo de tomada de decisão de consumo, recebendo importância nos estudos deste tema, dentre eles a identidade e a cultura.

Conforme Brum Neto et al. (2008), a identidade existe em função da cultura, pois ela é capaz de exprimir suas características distintivas mais marcantes, às quais denominamos de valores culturais. Diante desta constatação, o reforço às origens identitárias e aos valores culturais fez surgir, no campo científico, a curiosidade pela compreensão da influência do etnocentrismo no consumo (SHIMP et al., 1987; OBERMILLER et al., 1989; STREHLAU et al., 2012; FERNÁNDEZ-FERÍN et al., 2013; LORENZ et al., 2015; DOSSIN et al., 2019).

O etnocentrismo corresponde ao sentimento de superioridade atribuído a um país frente a outros (OBERMILLER et al., 1989), em outras palavras, "é uma visão do mundo onde o nosso próprio grupo é tomado como centro de tudo e todos os outros são pensados através de nossos valores, nossos modelos, nossas definições do que é existência" (ROCHA, 2007). Isso implica dizer que, quando considerado no consumo, o consumidor etnocêntrico tende a dar preferência aos produtos da sua terra (FERNÁNDEZ-FERíN et al., 2013).

Neste sentido, a fim de se mensurar a influência do etnocentrismo no comportamento de consumo, Shimp et al. (1987) construíram e validaram a CETSCALE, uma escala com 17 afirmações capazes de traduzir o grau de etnocentrismo na tomada de decisões de consumo dos indivíduos.

No Brasil, identificou-se, até junho de 2019, a publicação de apenas uma aplicação desta escala, no estudo de Strehlau et al. (2012), realizado em São Paulo, estado considerado mais etnocêntrico do país (VELLOSO, 1993), indicou que as classes socioeconômicas mais baixas são significativamente mais etnocêntricas do que a classe socioeconômica mais alta, bem como as pessoas mais velhas apresentam maior sentimento etnocêntrico que as mais jovens, ratificando os resultados do estudo de Shimp et al. (1987). Para além do sentimento ligado ao patriotismo e nacionalismo, outros sentimentos surgem quando considerada as dimensões territoriais e diversidade cultural existentes no Brasil, são eles: o regionalismo e o bairrismo.

O regionalismo consiste em uma visão unionista que visa a superação do estadualismo e busca reforçar os aspectos culturais e sociais mais fortes das regiões do Brasil (FREYRE, 1996), distinguindo-se do bairrismo principalmente por apresentar características mais restritas ao local, reafirmando o local (bairro, cidade ou estado) como superior e mais importante que os demais, da mesma forma que o etnocentrismo atua, porém, distanciando-se de uma visão nacional e aproximando-se de uma dimensão menor e local (SANTOS, 2012).

Porém, apesar de possuir forte influência no comportamento social dos indivíduos, não foram encontrados, em consultas realizadas em junho de 2019, registros de estudos científicos que versem sobre a relação ente o bairrismo e o consumo nas bases de dados Spell, Scielo, Periódicos Capes, Ebsco e Google Scholar. Dessa forma, a presente pesquisa objetiva identificar se há relação entre o sentimento bairrista e a intenção de compra de produtos locais. 
Diante do exposto, este estudo se justifica teoricamente pela falta de pesquisas que estabeleçam essa relação na literatura de gestão, marketing e comportamento do consumidor; e, no campo gerencial, apresenta resultados que podem contribuir para a formulação de estratégias promocionais de produtos locais e estratégias de inserção e promoção de produtos advindos de outras localidades em territórios que apresentam sentimento fortemente bairrista.

\section{REVISÃO TEÓRICA}

\section{Comportamento do consumidor}

Apesar de ter o início dos seus estudos atrelado à década de 1960, a área de pesquisa de comportamento do consumidor, nos últimos anos, tem vivenciado grandes mudanças que estimulam e assustam os profissionais de marketing, uma vez que a modernidade tem impulsionado e moldado o comportamento de consumo em um ritmo muito rápido (MOTHERSBAUGH et al., 2019).

Neste sentido, Mothersbaugh et al. (2019) explicitam que as mudanças do comportamento do consumidor impulsionam mudanças no marketing num sentido geral, pois novas estratégias precisam ser adotadas pelos profissionais da área, ficando cada vez mais evidente, segundo estes autores, que houve uma sucinta troca de poder nessa relação, do profissional de marketing para os consumidores, o que fez o marketing, da atualidade, moldar suas estratégias e abordagens afastando-se de uma postura de massificação e generalização para abordagens mais focadas e voltadas para a diferenciação.

Para compreender-se a evolução do pensamento acerca do comportamento de consumo, Richers (1984) caracterizava este tipo de comportamento como sendo o conjunto de atividades mentais e emocionais realizadas pelo consumidor no momento de seleção, compra e uso de produtos e serviços que visassem à satisfação de suas necessidades e desejos. Décadas mais tarde, porém, Kotler et al. (2012) viriam a definir este mesmo comportamento como sendo "o estudo de como indivíduos, grupos e organizações selecionam, compram, usam e descartam bens, serviços, ideias ou experiências para satisfazer suas necessidades e desejos".

Neste mesmo direcionamento, Solomon (2016) define o comportamento do consumidor como uma área extensa que estuda os "processos envolvidos quando indivíduos ou grupos selecionam, compram, usam ou descartam produtos, serviços, ideia ou experiências para satisfazerem necessidades e desejos".

Trazendo uma visão mais atualizada e ampla, Mothersbaugh et al. (2019) afirmam que o campo do comportamento do consumidor aborda "o estudo de indivíduos, grupos e organizações e o processo que eles usam para selecionar, obter, usar e dispor de produtos, serviços, experiências ou ideias para satisfazer necessidades e o impacto que esses processos têm sobre o consumidor e a sociedade".

Desse modo, Solomon (2016) e Mothersbaugh et al. (2019) enfatizam o quanto o estudo do comportamento de consumo é um processo complexo e multidimensional e o que as decisões de compra do consumidor, em geral, envolvem várias etapas e são influenciadas por vários fatores. Engel et al. (2000) já ressaltavam que o conhecimento dos diversos fatores que influenciam o comportamento de compra de um 
indivíduo é bastante importante para que os gestores e profissionais de marketing possam considerar efetivamente os desejos e necessidades do consumidor e, assim, orientar suas ofertas para o mercado.

Dentre os fatores que exercem maior influência no comportamento de consumo, Kotler et al. (2012) afirmam que estes são em maior quantidade os fatores culturais, sociais e pessoais, com maior e mais profunda influência exercida pelos fatores culturais, como pode ser observado na Figura 1. Tal afirmação é corroborada por Solomon (2016), Mothersbaugh et al. (2019) ao afirmarem que o poder da influência cultural, principalmente no tocante às questões de valores culturais e cultura de consumo global e local.

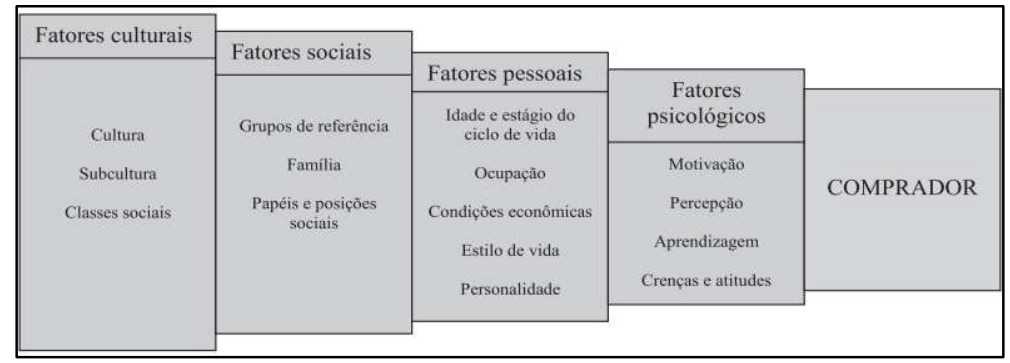

Figura 1: Graus de influência dos fatores no processo de tomada de decisão de compra. Fonte: Kotler (1998).

Assim, pode-se compreender que há uma forte influência cultural que é exercida socialmente sobre os indivíduos, de modo a influenciarem o seu comportamento na hora da tomada de decisão de compra. Dentre essas influências culturais, o etnocentrismo e o bairrismo podem ser apontados como fortes formadores da identidade de um povo e, por isso, sua relação com o consumo precisa ser melhor estudada. Sobre estes pontos, numa abordagem mais detalhada, apresenta-se o próximo tópico deste artigo.

\section{Etnocentrismo, bairrismo e consumo}

Uma vez compreendido que as influências culturais representam um grande peso na tomada de decisão de compra do consumidor, faz-se necessário entender um pouco mais sobre a questão dos valores culturais e como eles auxiliam na formação da identidade de um povo.

Stevens (2011) afirma que a cultura consiste de um conjunto de características próprias, capazes de diferenciar um grupo de outro, sendo ela constituída por crenças, tradições e valores. Neste sentido, Santos (2012) afirma que é a partir do conceito de cultura que emerge a identidade cultural, isto é, uma vez que o indivíduo compreende as crenças, valores e tradições do grupo em que está inserido, ele começa a despertar em si o sentimento de pertencimento ou não-pertencimento e identificação ou não-identificação para com o mesmo.

Tal concepção fez surgir, nos estudiosos do tema, diversos questionamentos, dentre eles a problematização acerca dos valores culturais frente ao discurso do consumo global. Hall (2005) afirma que as diferenças e distinções existentes nas diversas representações culturais, dentre elas a definição de identidade nacional e/ou local, estão sendo dizimadas a partir dos discursos de consumo global, pois nestes discursos busca-se uma "homogeneização cultural". Tal afirmação é corroborada por Moura (2019), uma vez que este autor enfatiza que a comunicação massiva e a globalização estão nivelando as diferenças de povos e comunidades, além de diminuir seus respectivos costumes próprios ao mesmo passo em que aumentam 
costumes globais em prol da virtualidade do mercado.

Apesar disso, Strehlau et al. (2010) enfatizam que produtos nacionais tendem a causar um efeito "país de origem" perceptível nos consumidores, em especial nos brasileiros. Tal afirmação também já havia sido apresentada em outros estudos, reforçando essa relação entre as informações de origem do produto e o quanto isso impacta no consumo (MAHESWARAN, 1994; CATEORA, 1999; STEENKAMP et al., 2003; MIRANDA, 2017; DOSSIN et al., 2019). Nesta perspectiva, observa-se o olhar do consumidor para o produto, considerando que exista uma visão etnocêntrica.

Ao considerar que uma visão etnocêntrica está diretamente relacionada cum sentimentos de patriotismo e nacionalismo (SHIMP et al., 1987), diversos autores procuraram definir o termo à sua maneira. Bueno (1980) destacava que o etnocentrismo compreendia a tendência de um povo em considerar a sua cultura "como a medida de todas as culturas". Igualmente considerando como uma tendência, Matsumoto (1996) conceituou o etnocentrismo como a "tendência de ver o mundo através de seus próprios filtros culturais". Anos mais tarde, de forma mais completa e pessoal, Rocha (2007) definiu o termo como sendo uma "visão do mundo onde o nosso próprio grupo é tomado como centro de tudo e todos os outros são pensados e sentidos através dos nossos valores, nossos modelos, nossas definições do que é a existência".

No que compreende a relação do etnocentrismo com o consumo, Shimp et al. (1987) propuseram e validaram um instrumento de 17 itens ao qual denominaram de CETSCALE, este instrumento consiste de uma escala que mensura o grau do etnocentrismo e sua relação com o comportamento de consumo de indivíduos de determinados grupos.

A aplicação dos conceitos gerais de etnocentrismo no comportamento do consumidor resultou na criação do termo "consumo etnocêntrico" (BALABANIS et al., 2004). Na concepção de Shimp et al. (1987) e dos demais estudos realizados, o etnocentrismo consiste de uma tendência individual em que o indivíduo é tão nacionalista e patriótico que considera os produtos fabricados no seu país como superiores quando considerado a produtos de outras nacionalidades, este consumo etnocêntrico não necessariamente culmina na rejeição total dos produtos, mas em uma forte preferência à produtos nacionais (DALMORO et al., 2010), no entendimento de muitos destes consumidores comprar produtos estrangeiros é imoral e antipatriótico, pois fere a economia interna provoca desemprego (EVANSCHITZKY et al., 2008).

Nesta mesma linha de raciocínio, Strehlau et al. (2010), acreditam que o etnocentrismo do consumidor "influencia as percepções das marcas globais e locais, sendo considerado na propensão de compra dos produtos e serviços de determinada marca". Miranda (2017), por sua vez, afirma que o consumo "parece não estar mais voltado apenas para produtos e serviços, mas também para identidades, subjetividades e cultura", os resultados encontrados nos estudos de Shimp et al. (1987) evidenciaram a influência cultural nas tendências etnocêntricas no consumo destacando o nível de abertura para países estrangeiros, patriotismo, conservadorismo, sensibilidade a pressões sociais e maior grau de concordância com as opiniões de parentes e amigos como atenuantes do comportamento de consumo etnocêntrico.

Considerando que a identidade cultural - formada a partir dos fortes traços, valores, crenças e tradições - é a principal responsável por despertar e desenvolver o sentimento etnocêntrico, e 
compreendendo o Brasil como um país de dimensões continentais e, por isso, tão rico e diversos culturalmente, estudiosos das ciências sociais (VELLOSO, 1993; FEYRE, 1996) apontam o surgimento de indivíduos com sentimentos ainda mais restritos que o patriotismo despertado pelo etnocentrismo. A esses outros sentimentos denominam-se regionalismo e bairrismo.

O Dicionário Online de Português apresenta os termos regionalismo e bairrismo como sinônimos, diferenciando-os em sua conceituação como sendo o regionalismo uma característica daquilo que é particular e próprio de uma determinada região, isto é, uma qualidade que expressa costumes e tradições que lhes são regionais, e o bairrismo como uma adoração exagerada pelo lugar de nascimento, excluindo ou desprezando os demais lugares.

Neste sentido, ao observar as origens etimológicas das duas palavras pode-se perceber mais claramente a diferenciação entre elas, uma vez que o regionalismo consiste de 'Regional + ismo' e o bairrismo representa 'Bairro + ismo'. Em outras palavras, o regionalismo tende a ser um sentimento menos amplo que o etnocentrismo, porém, mais amplo que o bairrismo, sendo este último um sentimento mais restrito, focado nas particularidades próprias de um local muito bem delimitado como um estado ou uma cidade, por exemplo.

Lorenz et al. (2015) enfatizam que a regionalidade atribuída a diversos produtos se caracterizou como um importante critério na avaliação que os consumidores têm dos produtos e, principalmente, na tomada de decisão de compra do mesmo. Isto porque, dentre os processos de avaliação do consumidor entende-se que o aspecto afetivo é um dos mais significativos, compreendendo neste aspecto que, caso um consumidor tenha simpatia por determinada região, esta mesma simpatia será automaticamente transferida para o produto que apontar ser de lá (OBERMILLER et al., 1989; DOSSIN et al., 2019). Spini (2016) exemplifica o regionalismo a partir do Nordeste brasileiro, uma vez que este autor compreende a força nordestina a partir dos sentimentos de valoração regional e da valorização das tradições, peculiares aos moradores desta região.

Quando tratado o bairrismo, especificamente, a literatura científica ainda não traz um volume considerável de estudos sobre o tema. Ainda assim, o bairrismo é apresentado como uma característica de forte valorização histórica e cultural de determinados povos, sempre sobressaindo o seu 'bairro' quando em comparação a outros. Vide que, enquanto Freyre (1996) apresenta Pernambuco como um estado em que o seu povo é carregado por um sentimento estadualista e/ou bairrista, no sentido de reconhecimento de sua história de lutas, seus costumes, tradições e culinária típica - o que vai além das delimitações territoriais de regiões brasileiras -, Santos (2012) afirma que “a característica bairrista é comumente atribuída ao gaúcho, muitas vezes até pelo próprio gaúcho", como pode ser percebido, por exemplo, na institucionalização por parte do povo e órgãos governamentais do estado do Rio Grande do Sul, com a comemoração do "dia do gaúcho" e a existência de Centros de Tradições Gaúchas (CTG) espalhados por vários estados do país, demonstrando o reconhecimento dos gaúchos à sua história, valores e tradições culturais (SOUZA, 2006).

Diante destes cenários apontados na literatura, o presente estudo apresenta duas hipóteses, H1a e H1b, a saber: Hipótese 1a: A maior parte da população Pernambucana apresenta mais sentimento bairrista; Hipótese 1b: A maior parte da população Gaúcha apresenta mais sentimento bairrista. 
Para além destas hipóteses, visando compreender melhor a possível existência da relação entre o sentimento bairrista e o consumo de produtos locais, considera-se que outros fatores possam colaborar com a intenção deste tipo de compra, tais como a idade, o sexo biológico e a renda. Desta forma, este estudo apresenta ainda as seguintes hipóteses:

Quanto à idade: Hipótese 2a: Há diferença estatisticamente significativa de intenção de compra de produtos locais entre consumidores pernambucanos de diferentes faixas etárias; Hipótese $\mathbf{2}$ b: Há diferença estatisticamente significativa de intenção de compra de produtos locais entre consumidores gaúchos de diferentes faixas etárias.

Quanto ao sexo biológico: Hipótese 3a: Há diferença estatisticamente significativa de intenção de compra de produtos locais entre consumidores pernambucanos de diferentes sexos biológicos; Hipótese 3b: Há diferença estatisticamente significativa de intenção de compra de produtos locais entre consumidores gaúchos de diferentes sexos biológicos.

Quanto à renda: Hipótese 4a: Há diferença estatisticamente significativa de intenção de compra de produtos locais entre consumidores pernambucanos de diferentes faixas de renda; Hipótese 4b: Há diferença estatisticamente significativa de intenção de compra de produtos locais entre consumidores gaúchas de diferentes faixas de renda.

Assim, tendo sido apresentados os fundamentos teóricos necessários para a compreensão do sentimento bairrista e de como ele pode apresentar relação para com o consumo, e as hipóteses que nortearão as análises estatísticas desta pesquisa, o próximo tópico apresenta os procedimentos metodológicos realizados para a efetivação desta pesquisa.

\section{METODOLOGIA}

Tendo em vista o objetivo desta pesquisa, de identificar uma possível relação entre o bairrismo e a intenção de compra de produtos locais, partiu-se para uma investigação de caráter quantitativo, de natureza descritiva e exploratória, uma vez que, como apresentado anteriormente, o tema ainda se apresenta incipiente dentro da literatura acadêmica.

A escolha pela abordagem quantitativa deu-se através de uma amostra não-probabilística, visando quantificar os dados coletados de determinados grupos, permitindo generalizações a partir da aplicação de análises estatísticas (MALHOTRA, 2006). Para isso, o instrumento de coleta de dados utilizado foi uma survey online, criada e disponibilizada gratuitamente através da plataforma do Google Formulários.

Tendo em vista os apontamentos da literatura científica sobre o sentimento bairrista brasileiro, foram selecionados dois estados para constituírem o espaço amostral desta pesquisa, por compreender que ambos apresentaram acessibilidade aos pesquisadores para a coleta dos dados e também, principalmente, por serem identificados na literatura como sendo possuidores de fortes características bairristas, a saber, os estados selecionados foram: Pernambuco e Rio Grande do Sul.

De acordo com Alves (2018), Pernambuco "possui características socioculturais fortes, como o maior carnaval de rua, o movimento Mangue beat, a cultura do futebol e o bairrismo característico à cidade e aos 
recifenses", enquanto que Santos (2012) enfatiza que no Rio Grande do Sul "a característica bairrista é comumente atribuída ao gaúcho, muitas vezes pelo próprio gaúcho".

Dessa maneira, optou-se por utilizar como base para o questionário a CETSCALE, por ser uma escala já amplamente utilizada e validada internacionalmente, tendo, para esta pesquisa, os itens traduzidos e adaptados para a realidade brasileira, bem como a adaptação do contexto patriota e nacionalista para o sentimento bairrista. Vale salientar que, antes da aplicação, a escala traduzida e adaptada recebeu a revisão e validação de dois pesquisadores da área e contou com um pré-teste, realizado entre os dias 20 e 24 de junho, para detectar as possíveis deficiências dos enunciados das questões e dificuldades no preenchimento das respostas.

Foram gerados dois questionários finais, cada um com adaptação dos itens da CETSCALE para cada estado selecionado para esta pesquisa, configurando-os com termos que remetessem ao consumo local. Os mesmos tiveram seu acesso disponibilizado por meio online para respostas de indivíduos nascidos e moradores dos referidos estados. Foram incluídas, ainda, três perguntas-filtro cuja intenção foi de classificar os respondentes como 'bairristas' e 'não-bairristas' para posterior cruzamento e análise dos dados. O período de coleta dos formulários online foi de 25 de junho a 04 de julho de 2019, obtendo, ao fim deste período, um total de 228 respondentes válidos, sendo 113 destes do estado do Rio Grande do Sul e 115 advindos do estado de Pernambuco.

Os dados coletados foram analisados estatisticamente, utilizando-se o coeficiente de confiabilidade alfa de Cronbach, a estatística básica, o Teste $t$-Student e a análise de variância (ANOVA), utilizando as ferramentas disponibilizadas no Excel.

\section{Caracterização da Amostra}

O perfil da amostra total mostrou algumas divergências entre os dois cenários (pernambucano e gaúcho), como mostra a Tabela 1, porém essas diferenças não apresentam grande significância a ponto de comprometerem a resolução do objetivo deste estudo.

Tabela 1: Perfil dos respondentes da pesquisa.

\begin{tabular}{l|l|l} 
Informações & Pernambuco & Rio Grande do Sul \\
\hline Total de respondentes & 116 & 113 \\
\hline Idade média & 29 anos & 39 anos \\
\hline Renda média mensal & $48,2 \%$ de um a três salários mínimos & $63,5 \%$ mais de três salários mínimos \\
\hline Sexo biológico & $\begin{array}{l}54,8 \% \text { masculino } \\
45,2 \% \text { feminino }\end{array}$ & $59,3 \%$ feminino, 39,8\% masculino e 0,9\% hermafrodita
\end{tabular}

Observa-se, com base nos dados apresentados na Tabela 1, que a amostra pernambucana foi composta por 116 respondentes de idades entre 18 e 57 anos, sendo a idade média de 29 anos, moda de 29 anos e mediana de 28 anos, tendo idade mínima de 18 anos e máxima de 57 anos. Pouco mais da metade dos respondentes $(54,8 \%)$ são homens e $48,2 \%$ são mulheres. A renda média mensal mais apresentada $(48,2 \%)$ por estes indivíduos foi de um a três salários mínimos.

Ainda conforme a Tabela 1, a amostra gaúcha compreende 113 respondentes com idade média de 39 anos, moda de 31 anos e mediana de 35 anos, apresentando idade mínima de 18 anos e máxima de 71 anos. 
Desse total de respondentes, a maioria (59,3\%) identificou-se do sexo feminino, enquanto $39,8 \%$ identificaram-se homens e $0,9 \%$ hermafroditas. A renda média mensal mais informada por este grupo de respondentes foi de acima de três salários mínimos.

\section{RESULTADOS E DISCUSSÃO}

Com a finalidade de avaliar a confiabilidade do questionário e validar a consistência interna das escalas utilizadas, realizou-se a aplicação do coeficiente alfa de Cronbach. Este coeficiente é uma propriedade inerente do padrão de resposta da população estudada, não representando apenas uma característica da escala por si só (STREINER, 2003; ALMEIDA et al., 2010). Neste sentido, obteve-se como resultados nas perguntas referentes ao bairrismo (que compreendiam afirmações referentes ao orgulho e a importância atribuídas pelos respondentes aos estados selecionados neste estudo) o alfa para os pernambucanos foi de 0,70 (aceitável) e 0,86 (muito bom) entre os gaúchos. No que se refere à Cetscale adaptada para o contexto bairrista, a adaptação apresentou alfas superiores à 0,90 em ambas situações. No questionário para pernambucanos o alfa foi de 0,95 , enquanto que no questionário para gaúchos foi de 0,96 . Ambos resultados demonstram elevada consistência interna dos questionários.

As três perguntas-filtro inseridas no início do formulário direcionavam para um panorama acerca do sentimento bairrista apresentado pelos respondentes de cada estado. Com base nas respostas recebidas percebeu-se que um grande percentual de ambos os estados demonstrou possuir este sentimento. Tratando esta realidade a partir de números percentuais, observou-se que $95,8 \%$ entre os pernambucanos demonstrou sentir orgulho do estado, frente à $84,1 \%$ dos gaúchos que demonstraram o mesmo sentimento. Dentre os pernambucanos, 90,5\% consideram este o melhor estado do Brasil e 92,3\% o consideram o estado mais importante do Nordeste. Já entre os gaúchos, $76 \%$ concordaram com a afirmação de que o Rio Grande do Sul é o melhor estado do Brasil e 79,7\% acreditam que este é o estado mais importante da região Sul.

Quando analisados separadamente, é possível perceber que, apesar dos respondentes de ambos os estados apresentarem alto grau de sentimento bairrista, os pernambucanos sobressaíram-se em valores percentuais. Dos 116 pernambucanos que compõem a amostra final, por exemplo, 102 foram classificados com sentimento mais bairrista, enquanto que entre os gaúchos esse total foi de 79 respondentes, dentre os 113 que compunham a amostra final.

A fim de testar $\mathrm{H} 1 \mathrm{a}$ e H1b, fez-se uso do Teste t-Student para a amostra pernambucana e a amostra gaúcha, apresentados as tabelas 2 e 3. Para tanto, o grau de sentimento bairrista (diferenciado entre 'menos' e 'mais' bairrista) considera as médias das respostas dos participantes pernambucanos e gaúchos quanto às três afirmações de posicionamento de seus estados. Tendo em vista que foram utilizadas escalas Likert de 7 pontos, foram consideradas para o nível 'menos bairrista' as médias até 5 , enquanto que para os 'mais bairristas' considerou-se as notas superiores a este valor.

Considerando a significância de $95 \%(\operatorname{sig}=0,05)$ e analisando o valor do Teste t resultante da comparação entre os pernambucanos menos bairristas e mais bairristas, pode-se concluir que a partir do resultado 0,0007 (isto é, muito menor que 0,05 ) identifica-se uma diferença significante entre os grupos 'mais 
bairristas' e 'menos bairristas', ou seja, na amostra pernambucana o grupo 'mais bairrista' destacou-se como predominante. Os resultados do teste demonstram que mesmo se mais pernambucanos tivessem respondido ao questionário, é alta a probabilidade que a grande maioria fosse continuar com sentimento mais bairrista. Este resultado confirma a hipótese alternativa $\mathrm{H} 1 \mathrm{a}$.

Tabela 2: Teste t - Amostra pernambucana.

\begin{tabular}{lll}
\hline & Menos bairristas & Mais bairristas \\
\hline Média & 29,92857143 & 46,67647059 \\
Variância & 191,9175824 & 527,9437973 \\
Observações & 14 & $\mathbf{1 0 2}$ \\
Hipótese da diferença de média & 0 & \\
GI & 24 & \\
Stat $t$ & $-3,853981992$ & \\
$P(T<=t)$ uni-caudal & 0,000380711 & \\
t crítico uni-caudal & 1,71088208 & \\
$P(T<=t)$ bi-caudal & $\mathbf{0 , 0 0 0 7 6 1 4 2 3}$ & \\
t crítico bi-caudal & 2,063898562 & \\
\hline
\end{tabular}

Tabela 3: Teste $\mathrm{t}$ - Amostra gaúcha.

\begin{tabular}{lll}
\hline & Menos bairristas & Mais bairristas \\
\hline Média & 31,91176471 & 45,92405063 \\
Variância & 207,0525847 & 582,6351834 \\
Observações & 34 & $\mathbf{7 9}$ \\
Hipótese da diferença de média & 0 & \\
GI & 100 & \\
Stat $t$ & $-3,818627099$ & \\
$P(T<=t)$ uni-caudal & 0,000116464 & \\
t crítico uni-caudal & 1,660234326 & \\
$P(T<=t)$ bi-caudal & 0,000232928 & \\
t crítico bi-caudal & 1,983971519 & \\
\hline
\end{tabular}

A partir da tabela 3, é possível constatar que o Teste t resultante da comparação entre os gaúchos menos bairristas e mais bairristas também apresenta uma média superior para os consumidores mais bairristas com significância na distinção entre os dois grupos (menos bairristas e mais bairristas), uma vez que apresentou o resultado de 0,0002. Ou seja, também entre os gaúchos há uma predominância do grupo considerado como 'mais bairristas', portanto confirmando a hipótese alternativa H1b.

Para além do conhecimento acerca do sentimento bairrista, este estudo propôs-se a compreender se este sentimento apresenta relação com a intenção de compra dos consumidores. Assim, apesar do alto índice de sentimento bairrista, quando pesquisado, especificamente, sua relação com o consumo (intenção de compra de produtos locais), observou-se, a partir da estatística básica, que ambos os estados apresentaram algo grau de discordância à aversão a produtos e serviços de fora de seus estados (81\% dos respondentes pernambucanos e $75 \%$ dos respondentes gaúchos). Isto é, de maneira geral, tanto os pernambucanos quanto os gaúchos não identificam a compra de produtos advindos de outros estados ou países como uma situação problemática, apesar de $44 \%$ dos pernambucanos e $42,4 \%$ dos gaúchos concordarem com a afirmativa de que é sempre melhor comprar produtos locais.

Considerando as diferenças entre faixas etárias dos consumidores pernambucanos, por apresentar idades variando entre 18 e 57 anos, foram criados quatro grupos de faixas de idades compreendendo intervalos de 10 anos. No caso dos gaúchos, como a idade variou de 18 anos (mínima) a 71 anos (máxima), respeitando o intervalo de 10 anos, foram criados seis grupos de faixas etárias. Tais grupos foram analisados, 
com base nas respostas aos 17 itens da CETSCALE adaptada ao bairrismo, por meio da análise de variância (ANOVA) adequada para testar a hipótese $\mathrm{H} 2 \mathrm{a}$ e H2b, os resultados estão apresentados nas tabelas 4 e 5.

Tabela 4: ANOVA - Faixas etárias dos consumidores pernambucanos.

\begin{tabular}{|c|c|c|c|c|c|c|}
\hline Grupo & Contagem & Soma & Média & Variância & & \\
\hline de 18 a 28 anos & 65 & 2755 & 42,38462 & 454,8966 & & \\
\hline de 29 a 38 anos & 41 & 1860 & 45,36585 & 487,1878 & & \\
\hline de 39 a 48 anos & 5 & 228 & 45,6 & 749,3 & & \\
\hline de 49 a 58 anos & 5 & 337 & 67,4 & 1181,3 & & \\
\hline \multicolumn{7}{|l|}{ ANOVA } \\
\hline Fonte da variação & $S Q$ & $g l$ & $M Q$ & $F$ & valor- $P$ & F crítico \\
\hline Entre grupos & 2946,91 & 3 & 982,3034 & 1,95333 & 0,125124 & 2,685643 \\
\hline Dentro dos grupos & 56323,3 & 112 & 502,8866 & & & \\
\hline Total & 59270,21 & 115 & & & & \\
\hline
\end{tabular}

O objetivo desse teste é verificar se as diferenças entre as médias dos diferentes grupos são significativas. Como pode ser observado nos dados apresentados da Tabela 4, o valor-p está acima do nível de significância adotado de 0,05 (valor- $P=0,12$ ), isso significa que não há diferenças estatística significativas entre os grupos de faixas etárias dos consumidores pernambucanos. $O$ valor de $F(1,95)$ abaixo do valor do $F$ crítico $(2,68)$ também aponta para a inexistência de diferenças significativas. Estes resultados rejeitam a hipótese alternativa $\mathrm{H} 2 \mathrm{a}$, portanto não há diferenças estatisticamente significativas da intenção de compra de produtos locais entre os grupos de faixas etárias.

Tabela 5: ANOVA - Faixas etárias dos consumidores gaúchos.

\begin{tabular}{|c|c|c|c|c|c|c|}
\hline Grupo & Contagem & Soma & Média & Variância & & \\
\hline de 18 a 28 anos & 23 & 876 & 38,08696 & 337,8103 & & \\
\hline de 29 a 38 anos & 43 & 1845 & 42,90698 & 717,3721 & & \\
\hline de 39 a 48 anos & 22 & 894 & 40,63636 & 390,2424 & & \\
\hline de 49 a 58 anos & 11 & 493 & 44,81818 & 523,3636 & & \\
\hline de 59 a 68 anos & 12 & 551 & 45,91667 & 426,0833 & & \\
\hline de 69 a 71 anos & 2 & 54 & 27 & 128 & & \\
\hline \multicolumn{7}{|l|}{ ANOVA } \\
\hline Fonte da variação & $S Q$ & $g l$ & $M Q$ & $F$ & valor-P & F crítico \\
\hline Entre grupos & 1140,265 & 5 & 228,053 & 0,437266 & 0,821642 & 2,299234 \\
\hline Dentro dos grupos & 55805,1 & 107 & 521,543 & & & \\
\hline Total & 56945,36 & 112 & & & & \\
\hline
\end{tabular}

O resultado da análise estatística da amostra Gaúcha demonstrados na Tabela 5 aponta para um resultado semelhante ao da amostra pernambucana, em que o valor-P apresentado foi de 0,82 , não apresentando significância estatística. Como descrito e apresentado anteriormente, apesar de apresentar seis grupos de faixas etárias, a amostra gaúcha também não demonstrou diferenças significativas, entre as médias, em relação à intenção de compra de produtos locais. Dessa forma, os dados indicam que, apesar do alto grau de sentimento bairrista apresentado por consumidores pernambucanos e gaúchos, este fator não se reflete na intenção de compra de produtos locais, quando analisados a partir das faixas etárias.

Quando comparados em relação ao sexo biológico, os consumidores de Pernambuco, que se autodeclararam como pertencentes ao sexo masculino ou feminino, sendo apenas 2 grupos fora realizado o Teste $t$-Student para comparar os grupos a fim de testar a validade da hipótese H3a. 
Tabela 6: Teste t - Diferenças por sexo biológico (Pernambuco).

\begin{tabular}{lll}
\hline & Masculino & Feminino \\
\hline Média & 40,21875 & 50,1153846 \\
Variância & 424,427579 & 582,770739 \\
Observações & 64 & 52 \\
Hipótese da diferença de média & 0 & \\
GI & 101 & \\
Stat $t$ & $-2,34317427$ & \\
$\mathrm{P}(\mathrm{T}<=\mathrm{t})$ uni-caudal & 0,01054013 & \\
t crítico uni-caudal & 1,66008063 & \\
$\mathrm{P}(\mathrm{T}<=\mathrm{t})$ bi-caudal & $\mathbf{0 , 0 2 1 0 8 0 2 7}$ & \\
t crítico bi-caudal & 1,983731 & \\
\hline
\end{tabular}

A partir da observação e análise da Tabela 6, é possível perceber que o valor de $t$ menor que $0,05(\mathrm{t}=$ 0,02 ), demonstra que existe diferença significativa entre o comportamento dos consumidores femininos e masculinos no que se refere à intenção de compra considerando o sentimento bairrista. Quando analisadas as médias e observações das respostas, percebe-se que, apesar do maior número de respondentes ter sido de indivíduos do sexo masculino, a média superior das respostas foi dentro do grupo de consumidores do sexo feminino. Isto quer dizer que, as mulheres apresentam maior grau de influência do sentimento bairrista na intenção de compra dos produtos locais. Deste modo a H3a é aceita para a amostra pernambucana.

Em relação ao sexo biológico, dentre os respondentes gaúchos, foram autodeclarados três sexos: masculino, feminino e hermafrodita. Assim, para a realização da mesma análise foi utilizada a análise de variância (ANOVA), uma vez que compreende três grupos e não apenas dois (como anteriormente realizado em Pernambuco) impossibilitando a aplicação do Teste t.

Tabela 7: ANOVA - Diferenças por sexo biológico (Rio Grande do Sul).

\begin{tabular}{|c|c|c|c|c|c|c|}
\hline Grupo & Contagem & Soma & Média & Variância & & \\
\hline Masculino & 45 & 1883 & 41,84444 & 548,8162 & & \\
\hline Feminino & 67 & 2774 & 41,40299 & 493,7291 & & \\
\hline Hermafrodita & 1 & 56 & 56 & & & \\
\hline \multicolumn{7}{|l|}{ ANOVA } \\
\hline Fonte da variação & $S Q$ & Gl & $M Q$ & $F$ & valor-P & F crítico \\
\hline Entre grupos & 211,3323 & 2 & 105,6662 & 0,204873 & 0,815061 & 3,078819 \\
\hline Dentro dos grupos & 56734,03 & 110 & 515,7639 & & & \\
\hline Total & 56945,36 & 112 & & & & \\
\hline
\end{tabular}

Como percebido na Tabela 7, o valor-P de 0,8 é muito superior ao nível de significância adotado $(0,05)$. Desta forma, conclui-se que, diferentemente do resultado obtido na amostra pernambucana, dentre os consumidores gaúchos, o sexo biológico (masculino, feminino ou hermafrodita) não apresenta diferença significativa na relação entre o bairrismo e a intenção de compra, portanto rejeitando a hipótese H3b.

Por fim, em relação à renda, as amostras pernambucana e gaúcha foram divididas em três grupos: menos de um salário mínimo, de um a três salários mínimo, e mais de três salários mínimos. É importante destacar que dentre os pernambucanos participantes desta pesquisa a maioria estava na faixa que compreende de um a três salários mínimos, enquanto que, dentre os participantes gaúchos a maior parte estava na faixa de mais de três salários mínimos. Tal situação pode ser explicada quando observada a média e mediana das idades (Pernambuco apresentou idade média de 29 anos e mediana 28, enquanto que o Rio Grande do Sul apresentou idade média de 39 anos e mediana de 35). 
Tabela 8: ANOVA - Faixas de renda (Pernambuco).

\begin{tabular}{|c|c|c|c|c|c|c|}
\hline Grupo & Contagem & Soma & Média & Variância & & \\
\hline Menos de um salário mínimo & 27 & 1249 & 46,25926 & 477,3533 & & \\
\hline De um a três salários mínimos & 55 & 2456 & 44,65455 & 559,5266 & & \\
\hline Mais de três salários mínimos & 34 & 1475 & 43,38235 & 500,607 & & \\
\hline \multicolumn{7}{|l|}{ ANOVA } \\
\hline Fonte da variação & $S Q$ & $g l$ & $M Q$ & $F$ & valor- $P$ & F crítico \\
\hline Entre grupos & 124,5559 & 2 & 62,27797 & 0,118984 & 0,887933 & 3,076574 \\
\hline Dentro dos grupos & 59145,65 & 113 & 523,4128 & & & \\
\hline Total & 59270,21 & 115 & & & & \\
\hline
\end{tabular}

A Tabela 8 demonstra que o valor- $P$ foi superior ao nível de significância de 0,05 (valor- $P=0,88)$ e, por este motivo, conclui-se que não há diferença significativa nesta relação das rendas com a intenção de compra de produtos locais.

No que compreende a análise das rendas da amostra gaúcha, a Tabela 10 aponta que, assim como observado em Pernambuco, o valor-P apresentou resultado maior do que a significância, porém com pouca diferença (valor- $P=0,069)$, isto é, não há diferenças significativas entre a relação das rendas com a intenção de compra de produtos locais, portanto a hipótese H4a é rejeitada.

Tabela 10: ANOVA - Faixas de renda (Rio Grande do Sul).

\begin{tabular}{|c|c|c|c|c|c|c|}
\hline Grupo & Contagem & Soma & Média & Variância & & \\
\hline Menos de um salário mínimo & 5 & 170 & 34 & 134,5 & & \\
\hline De um a três salários mínimos & 34 & 1666 & 49 & 771,3333 & & \\
\hline Mais de três salários mínimos & 74 & 2877 & 38,87838 & 387,0672 & & \\
\hline \multicolumn{7}{|l|}{ ANOVA } \\
\hline Fonte da variação & $S Q$ & $g l$ & $M Q$ & $F$ & valor- $P$ & F crítico \\
\hline Entre grupos & 2697,457 & 2 & 1348,729 & 2,734855 & 0,069319 & 3,078819 \\
\hline Dentro dos grupos & 54247,91 & 110 & 493,1628 & & & \\
\hline Total & 56945,36 & 112 & & & & \\
\hline
\end{tabular}

O mesmo teste fora realizado com a amostra Gaúcha, observa-se que o valor-P também fora acima do nível de significância adotado $(0,05)$, além disso o valor de $F$ é menor que o valor $F$ crítico resultante, portando não diferenças significativas importantes entre os grupos de diferentes faixas de renda e a intenção de compra de produtos locais. Este resultado rejeita a última hipótese testada H4b.

\section{CONCLUSÕES}

Este estudo teve como principal objetivo identificar se há relação entre o sentimento bairrista e a intenção de compra de produtos locais. Assim, em um primeiro momento foram analisados os sentimentos bairristas dentro das amostras selecionadas de acordo com referências da literatura científica, que compreenderam respondentes dos estados de Pernambuco e Rio Grande do Sul.

Corroborando com a literatura, identificou-se que os pernambucanos e os gaúchos demonstraram alto grau de sentimento bairrista, sendo que, dentre os respondentes de Pernambuco, houve maior número de indivíduos mais bairristas do que dentre os respondentes do Rio Grande do Sul. Este fato pode ser explicado devido aos recentes acontecimentos políticos e econômicos que acometem o estado do Rio Grande do Sul e podem ter influenciado uma parcela dos respondentes gaúchos a discordarem das afirmações quanto a considerarem o estado como 'o melhor do Brasil' e 'o mais importante da região Sul'. 
Diante deste fato, muito embora o percentual maior de grau de bairrismo tenha sido encontrado nos respondentes pernambucanos, os resultados das análises estatísticas confirmaram as hipóteses H1a e H1b, portanto corroborando com os achados da literatura, que tanto em Pernambuco quanto no Rio Grande do Sul, há predominância de indivíduos com sentimentos 'mais bairristas'.

Apesar da confirmação das duas hipóteses relacionadas ao bairrismo, observou-se a partir dos testes estatísticos realizados que o sentimento bairrista não demonstrou significância quando relacionado à intenção de compra de produtos locais com ressalva à amostra pernambucana onde observou-se através do teste da hipótese H3a que há diferença estatisticamente significativa da intenção de compra de produtos locais entre os sexos biológicos, evidenciando que indivíduos do sexo masculino possuem maior intenção de compras de produtos locais que o os indivíduos do sexo feminino

A rejeição das hipóteses $\mathrm{H} 2 \mathrm{a}, \mathrm{H} 2 \mathrm{~b}, \mathrm{H} 3 \mathrm{~b}, \mathrm{H} 4 \mathrm{a}$ e $\mathrm{H} 4 \mathrm{~b}$, demonstra que quando analisamos sexo biológicos da amostra gaúcha, idades e rendas dos gaúchos e pernambucanos não encontramos diferenças estatísticas significativas que evidencie uma forte influência do sentimento bairrista na intenção de compra de produtos produzidos localmente. Dessa forma, é possível compreender que o bairrismo está mais relacionado ao orgulho e valorização da importância dos fatores históricos e culturais de uma população do que, propriamente, ao consumo.

Outro ponto a ser destacado é que tanto os respondentes pernambucanos quanto os gaúchos se mostraram intencionados a realizarem compras de produtos produzidos fora de seus estados, porém, em ambos os casos se observou a existência de uma valorização à produção e ao consumo de produtos produzidos em seus estados.

Assim, conclui-se que, do ponto de vista gerencial, valorizar a cultura e as tradições históricas de uma população em suas peças publicitárias é importante para reforçar a valorização das questões do sentimento de bairrismo deste povo, de modo a tornar a marca ou empresa mais próxima de seus consumidores. Porém, apesar da alta expressividade deste sentimento, ele não reflete em uma relação com o comportamento de consumo dos indivíduos, no que diz respeito à intenção de compra de produtos locais. Talvez a globalização dos mercados e a consequente hegemonização cultural, apontadas por Hall (2005) e Moura (2019) sejam justificativas para esta não-aversão ao consumo de produtos de outros lugares, o que também fora evidenciado nos estudos seminais de Shimp et al. (1987) e na aplicação brasileira da CETSCALE nos estudos de Strehlau et al. (2012).

Como toda pesquisa cientifica, está apresentou algumas limitações. Uma delas refere-se à quantidade de respondentes, por ser muito específico à nascidos e/ou residentes dos estados selecionados, houve baixa taxa de respostas dos questionários, porém nada que comprometesse a pesquisa e seus resultados. Assim também, a opção pela pesquisa quantitativa limita os resultados uma vez que é possível analisar o cenário como um todo, numa visão panorâmica, porém sem se ater aos 'porquês' do consumo ou não consumo, que seriam possíveis de serem compreendidos a partir da utilização de instrumentos de métodos qualitativos. Assim, sugere-se para estudos futuros pesquisas que utilizem de abordagem qualitativa por meio de entrevistas, observação ou etnografia, por exemplo, bem como estabelecer relações do bairrismo com outros 
comportamentos do consumo, como aproximação e afastamento, e avaliação de anúncios e elementos promocionais.

\section{REFERÊNCIAS}

ALMEIDA, D.; SANTOS, M. A. R.; COSTA, A. F. B.. Aplicação do coeficiente alfa de Cronbach nos resultados de um questionário para avaliação de desempenho da saúde pública. In: ENCONTRO NACIONAL DE ENGENHARIA DE PRODUÇÃO (ENEGEP), 30. Anais. São Carlos: São Paulo, 2010.

ALVES, R. C. A.. Consumo colaborativo e valores pessoais: um estudo sobre o comportamento de consumo dos usuários de Coworking em Recife. Monografia (Bacharelado em Administração) - Universidade Federal do Rio Grande do Norte, Natal, 2018.

BALABANIS, G.; DIAMANTOPOULOS, A.. Domestic country bias, country-of-origin effects, and consumer ethnocentrism: a multidimensional unfolding approach. Journal of the Academy of Marketing Science, v.32, n.1, p.80-95, 2004.

BUENO, F. S.. Dicionário escolar da língua portuguesa. 11 ed. Rio de Janeiro: Fenam, 1980.

BRUM NETO, H. B.; BEZZI, M. L.. Regiões culturais: a construção de identidades no Rio Grande do Sul e sua manifestação na paisagem gaúcha. Uberlândia: Sociedade e Natureza, 2008.

CATEORA, P. R.. International marketing. 10 ed. Boston: International Edition, 1999.

DOSSIN, A.; LAZZARI, F.; MILAN, G. S.; PICCIN, T.. A influência da Denominação de Origem na Percepção de Consumidores de Café: Um Estudo com Brasileiros e Franceses. Revista Eletrônica de Ciência Administrativa, v.18, n.1, 2019.

DALMORO, M.; ROSSI, C.. Além do made in...: uma análise exploratória das teorias acerca do comportamento de compra de produtos importados. Revista de Gestão dos Países de Língua Portuguesa, v.9, n.3, p.2-10, 2010.

ENGEL, J. F.; BLACKWELL, R. D.; MINIARD, P. W. Comportamento do Consumidor. 8 ed. Rio de Janeiro: LTC, 2000.

EVANSCHITZKY, H.; FLORIAN, V.; WANGENHEIM, D.; WOISETSCHLA, G.; BLUT, M.. Consumer ethnocentrism in the German market. International Marketing Review, v.25, n.1, p.7-32, 2008

FERNÁNDEZ-FERRÍN, P.; BANDE-VILELA, B.. Regional ethnocentrism: antecedents, consequences and moderating effects. Food Quality and Preference, v.30, n.2, p.299-308, 2013.

FREYRE, G.. Manifesto Regionalista. 7 ed. Recife: Massangana, 1996.

HALL, S.. A identidade cultural na pós-modernidade. Rio de Janeiro: DP\&A, 2005.
KOTLER, P.. Administração de marketing: análise, planejamento, implementação e controle. 5 ed. São Paulo: Atlas, 1998.

KOTLER, P.; KELLER, K. L.. Administração de marketing. 14 ed. São Paulo: Pearson Education do Brasil, 2012

LORENZ, B. A.; HARTMANN, M.; SIMONS, J.. Impacts from region-of-origin labeling on consumer product perception and purchasing intention: causal relationships in a TPB based model. Food Quality and Preference, v.45, p.149-157, 2015.

MAHESWARAN, D.. Country of origin as a stereotype: effects of consumer expertise and attribute strength on product evaluations. The Journal of Consumer Research, v.21, n.2, p.354-65, 1994.

MALHOTRA, N.. Pesquisa de marketing: uma orientação aplicada. 4 ed. Porto Alegre: Bookman, 2006.

MATSUMOTO, D.. Culture and Psychology. Pacific Grove: Brooks Cole, 1996

MIRANDA, A. P. A.. Cultura local e marca: relações entre comunicação e grupos de referência, o caso Festival Folclórico de Parintins no Amazonas brasileiro. Anuário Unesco/Metodista de Comunicação Regional, n.21, p.145150, 2017.

MOTHERSBAUGH, D. L.; HAWKINS, D. I.. Comportamento do consumidor: construindo a estratégia de marketing. 13 ed. Rio de Janeiro: Elsevier, 2019.

MOURA, V. A.. Novas maneiras de ressignificar, de participar e de colaborar na era da mobilidade informacional.

Textolivro: Linguagem e tecnologia, Belo Horizonte, v.12, n.1, p.112-122, 2019.

OBERMILLER, C.; SPANGENBERG, E.. Exploring the effects of country of origin labels: an information-processing framework. Advances in Consumer Research, v.16, p.454459, 1989.

RICHERS, R.. O enigmático mais indispensável consumidor: teoria e prática. Revista da Administração, v.19, n.3, p.4656, 1984. DOI: https://doi.org/10.1016/rausp.v19i3.167512

ROCHA, E. P. G.. O que é etnocentrismo. São Paulo: Brasiliense, 2007.

SANTOS, L. R.. Comerciais da cerveja polar export: bairrismo e efeitos de sentido. Monografia (Licenciatura em Letras) Universidade Regional do Noroeste do Rio Grande do Sul, ljuí, 2012.

SHIMP, T. A.; SHARMA, S.. Consumer Ethnocentrism Construction and Validation of the CETSCALE. Journal of Marketing Research, v.24, n.3, p.280-289, 1987. 
SPINI, A. P.. Regionalismo e identidade nacional nos filmes de Humberto Mauro dos anos de 1920. Fato \& Versões: Revista de História, v.8, n.15, p.9-24, 2016.

SOLOMON, M. R.. O Comportamento do Consumidor: comprando, possuindo e sendo. 11 ed. Porto Alegre: Bookman, 2016.

SOUZA, C.. Gaúchos em Roraima: memória, regionalismo e identidade. Estudos Ibero-Americanos, v.32, n.1, p.199-207, 2006.

STEENKAMP, J.-B. E. M.; BATRA, R.; ALDEN, D. L.. How perceived brand globalness creates brand value. Journal of International Business Studies, v.34, n.1, p.53-65, 2003.

STEVENS, L.. Mídia, Identidade e Representação: uma análise da publicidade televisiva da cerveja Polar Export. Santa Maria: UFSM, 2011
STREHLAU, V. I.; PONCHIO, M. C.; RIEGEL, V.. País de origem e etnocentrismo na avaliação da imagem de marca global: um estudo sobre o McDonald's. Internext: Revista Eletrônica de Negócios Internacionais, v.5, n.2, p.23-45, 2010.

STREHLAU, V. I.; PONCHIO, M. C.; LOEBEL, E.. Uma avaliação da escala de etnocentrismo do consumidor (CETSCALE): indícios do Brasil. Brazilian Business Review, v.9, n.4, p.108132, 2012.

STREINER, D. L.. Being inconsistente about consistency: when coeficiente alpha does and doesn't matter. Journal of Personality Assessment, v.80, p.217-222, 2003.

VELLOSO, M. P.. A brasilidade verde-amarela: nacionalismo e regionalismo paulista. Revisa Estudos Históricos. Rio de Janeiro, v.6, n.11, 1993.

A CBPC - Companhia Brasileira de Produção Científica (CNPJ: 11.221.422/0001-03) detém os direitos materiais desta publicação. Os direitos referem-se à publicação do trabalho em qualquer parte do mundo, incluindo os direitos às renovações, expansões e disseminações da contribuição, bem como outros direitos subsidiários. Todos os trabalhos publicados eletronicamente poderão posteriormente ser publicados em coletâneas impressas sob coordenação da Sustenere Publishing, da Companhia Brasileira de Produção Científica e seus parceiros autorizados. Os (as) autores (as) preservam os direitos autorais, mas não têm permissão para a publicação da contribuição em outro meio, impresso ou digital, em português ou em tradução. 